AperTO - Archivio Istituzionale Open Access dell'Università di Torino

\title{
Extrapulmonary neuroendocrine small and large cell carcinomas: a review of controversial diagnostic and therapeutic issues.
}

This is a pre print version of the following article:

Original Citation:

Availability:

This version is available http://hdl.handle.net/2318/140168

since

Published version:

DOI:10.1016/j.humpath.2013.03.016

Terms of use:

Open Access

Anyone can freely access the full text of works made available as "Open Access". Works made available under a Creative Commons license can be used according to the terms and conditions of said license. Use of all other works requires consent of the right holder (author or publisher) if not exempted from copyright protection by the applicable law. 


\title{
Extrapulmonary neuroendocrine small and large cell carcinomas: a review of controversial diagnostic and therapeutic issues ${ }^{25}$
}

\author{
Marco Volante MD $^{a, *}$, Nadia Birocco MD ${ }^{b}$, Gaia Gatti MD ${ }^{a}$, Eleonora Duregon MD ${ }^{a}$, \\ Katia Lorizzo MD ${ }^{c}$, Nicola Fazio MD ${ }^{c}$, Giorgio V. Scagliotti MD ${ }^{a}$, Mauro Papotti MD ${ }^{a}$
}

${ }^{a}$ Department of Oncology, University of Turin at San Luigi Hospital, 10043 Torino, Italy

${ }^{\mathrm{b}}$ Medical Oncology, San Giovanni Hospital Torino, 10126 Torino, Italy

${ }^{\mathrm{c}}$ Medical Oncology, European Institute of Oncology, 20141 Milan, Italy

Received 31 January 2013; revised 25 March 2013; accepted 27 March 2013

\author{
Keywords: \\ Neuroendocrine \\ carcinoma; \\ Extrapulmonary; \\ Small cell; \\ Large cell; \\ Pathology; \\ Chemotherapy; \\ $\mathrm{Ki}-67$
}

\begin{abstract}
Summary Extrapulmonary neuroendocrine carcinoma (EPNEC) is a heterogeneous and rare group of high-grade neoplasms occurring in different organs. They usually share a poor prognosis, but diagnostic and therapeutic options still include several controversial issues, due to the rarity of this condition and to differences in architecture and cell size, being some cases pure small cell carcinomas, other pure large cell neuroendocrine carcinomas and some others combined/mixed neuroendocrine carcinomas with a conventional non-neuroendocrine carcinoma. In addition, the therapeutic strategy varies in different organs (surgery and/or chemotherapy and/or radiation therapy and/or targeted treatments), and clinicians and pathologists are asked to interact to reach an accurate classification of every single case, as well as the most appropriate selection of the treatment options, even considering different time points of each EPNEC natural history. This overview highlights controversial pathological and clinical issues and summarizes possible solutions to most of such EPNEC-related problems.
\end{abstract}

(C) 2013 Published by Elsevier Inc.

\section{Introduction}

In a recent commentary on diagnostic and classification problems of neuroendocrine (NE) tumors [1], several frequently asked questions (FAQ) were discussed, and some tentative answers offered to specific topics. Among them, the issue of high grade, poorly differentiated NE carcinomas (NEC) was

\footnotetext{
Conflict of interest statement: K.L. is currently employed by Novartis Pharma. All other authors declare the absence of any conflict of interest.

* Corresponding author. Department of Oncology, University of Turin at St. Luigi Hospital, Regione Gonzole 10, 10043 Orbassano, Torino, Italy.

E-mail address: marco.volante@unito.it (M. Volante).
}

briefly addressed (FAQ \#4) with regard to their occurrence in several extrapulmonary organs, as either small cell carcinomas (SCC) or large cell NECs (LCNEC), apparently very similar to their well-known respective pulmonary counterparts $[2,3]$. In the literature, the occurrence of extrapulmonary poorly differentiated NECs (EPNEC) has been reported in single case reports (see review [4]), and only recently were relatively large series collected and analyzed from both clinical and pathological perspectives [5]. However, the pathological aspects as well as the therapeutic strategies of EPNEC still seem rather heterogeneous in the literature, and the present review collects the available diagnostic and therapeutic information on this tumor group, highlighting crucial issues and possible solutions. 


\section{Relevant issues and possible solutions}

\subsection{Issue 0 : organ distribution and incidence}

EPNECs are defined as malignant epithelial tumors having a totally or predominant NE differentiated cell population and high-grade features. They are rare or extremely rare outside the lung and can develop in virtually any location. Relatively large series were reported in the gastroenteropancreatic (GEP) area, including the esophagus [6], stomach [7,8], colon and rectum [9], and pancreas [10]. In addition, EPNECs of the small or large type were investigated in the prostate [11,12], bladder [13] and uterine cervix $[14,15]$. Overall, EPNECs account for no more than $3 \%$ of all malignancies in individual anatomical sites.

NECs have also been described in the skin for more than 40 years, under the generic term of Merkel cell carcinoma. Although the morphology of classical small cell forms is not different from that of small cell lung cancer, Merkel cell carcinoma has heterogeneous morphological and molecular features, as well as variable and peculiar clinical behavior and therapeutic implications. For these reasons it has been excluded from the present review.

\subsection{Issue 1}

\subsubsection{Problem: How to label these tumors?}

2.2.1.1. Solution: Use the general term EPNEC; quote synonyms. A relatively long list of different terms are currently used to label these tumors. They refer either to cell size (extrapulmonary small or LCNECs), to tumor grade (high-grade NEC, G3) or to loss of differentiation (poorly differentiated NE/endocrine carcinomas). In addition, the occurrence of combined small and large cell NEC has been reported not only in the lung but also in some other locations (stomach, gallbladder, bladder, etc), although this distinction is not considered of clinical or prognostic relevance in these organs (including the lung) [5]. The terminology used for such tumor type(s) is itself heterogeneous, being only partially derived by their largely more common pulmonary counterpart. In fact, for LCNEC in extrapulmonary organs, the original terminology proposed by Travis and coworkers for the corresponding lung tumors has often been adopted [3], whereas when series of pure NECs or mixed/combined carcinomas are investigated in the stomach or colon rectum or bladder, the nomenclature is more confused and either SCC or poorly differentiated NEC terms are used, often interchangeably. In our view, this is not appropriate, since pure SCC generally do not differ from their classical pulmonary counterpart (oat cell type), but all other variants including intermediate cell type (a definition included in previous classifications), LCNEC and combined NE/non-NECs actually display more complex morphological features, which cannot be directly addressed to one histological type.

Referring to the available World Health Organization (WHO) classifications, the 2010 WHO classification of tumors of the digestive system restricted the term "NEC" to poorly differentiated, clinically aggressive neoplasms, which are graded as G3 by definition [16]. Similar to the lung, these include small and large cell variants (or a combination of the two), being relatively common in the stomach and very rare in the pancreas. By contrast, in other WHO classification schemes (namely of the urogenital tract and breast/female genital organs) $[17,18]$ nomenclature per se is heterogeneous and include general terms such as NEC not otherwise specified or consider SCC type, only.

For practical purposes, in analogy to what is proposed in the GEP system, the nomenclature of EPNEC is advisable, with a subspecification of either small or large cell types. Such uncommitted terminology would allow to compare the pathological features and the real prevalence of EPNEC, as well as to address the issue of their most appropriate therapeutic strategy.

\subsection{Issue 2}

\subsubsection{Problem: Differential diagnosis of small and large cell NEC}

2.3.1.1. Solution: Identify architectural patterns, cytological features, and appropriate immunophenotype. EPNEC of the classical small cell type has uniform morphological features, irrespective of the organ in which they develop, overall similar to those of the pulmonary counterpart (Fig.). Conversely, other EPNEC forms, including pure LCNEC and combined small and large cell carcinomas, have peculiar features with differences in various locations (Table 1).

From a pathological point of view, the distinction between small and large cell tumors is of relevance for the purpose of a correct classification of the tumor itself and, above all, an accurate differential diagnosis from other

Fig. A and B, A biopsy specimen of a small cell NEC of the stomach (H\&E; original magnification $\times 200$ and $\times 400$ for $\mathrm{A}$ and $\mathrm{B}$, respectively). C-F, A case of LCNEC of the rectum, deeply invasive (C), composed of large atypical cells with irregular nuclei having prominent nucleoli (D), typical dot-like patterned chromogranin A expression (E), and very high Ki-67 proliferation index (F) (C and D, H\&E; E and F, immunoperoxidase; original magnification: $\mathrm{C}, \times 100$; D and F, $\times 400 ; \mathrm{E}, \times 200$ ). G-I, A mixed adeno-NEC of the stomach showing two distinct tumor cell populations $(\mathrm{G})$ with chromogranin A positivity restricted to the NE (large-cell) component $(\mathrm{H})$ and a single lymph node micrometastasis from the adenocarcinomatous component (I) (G and I, H\&E; H, immunoperoxidase; original magnification: G, $\times 200$; H, $\times 100$; I, $\times 400)$. J, A biopsy specimen of a case of small cell carcinoma of the bladder with extensive crushing artifacts $(\mathrm{H} \& \mathrm{E}$; original magnification $\times 200)$. K, A case of LCNEC of the renal pelvis $(\mathrm{H} \& \mathrm{E}$; original magnification $\times 200$ ). 

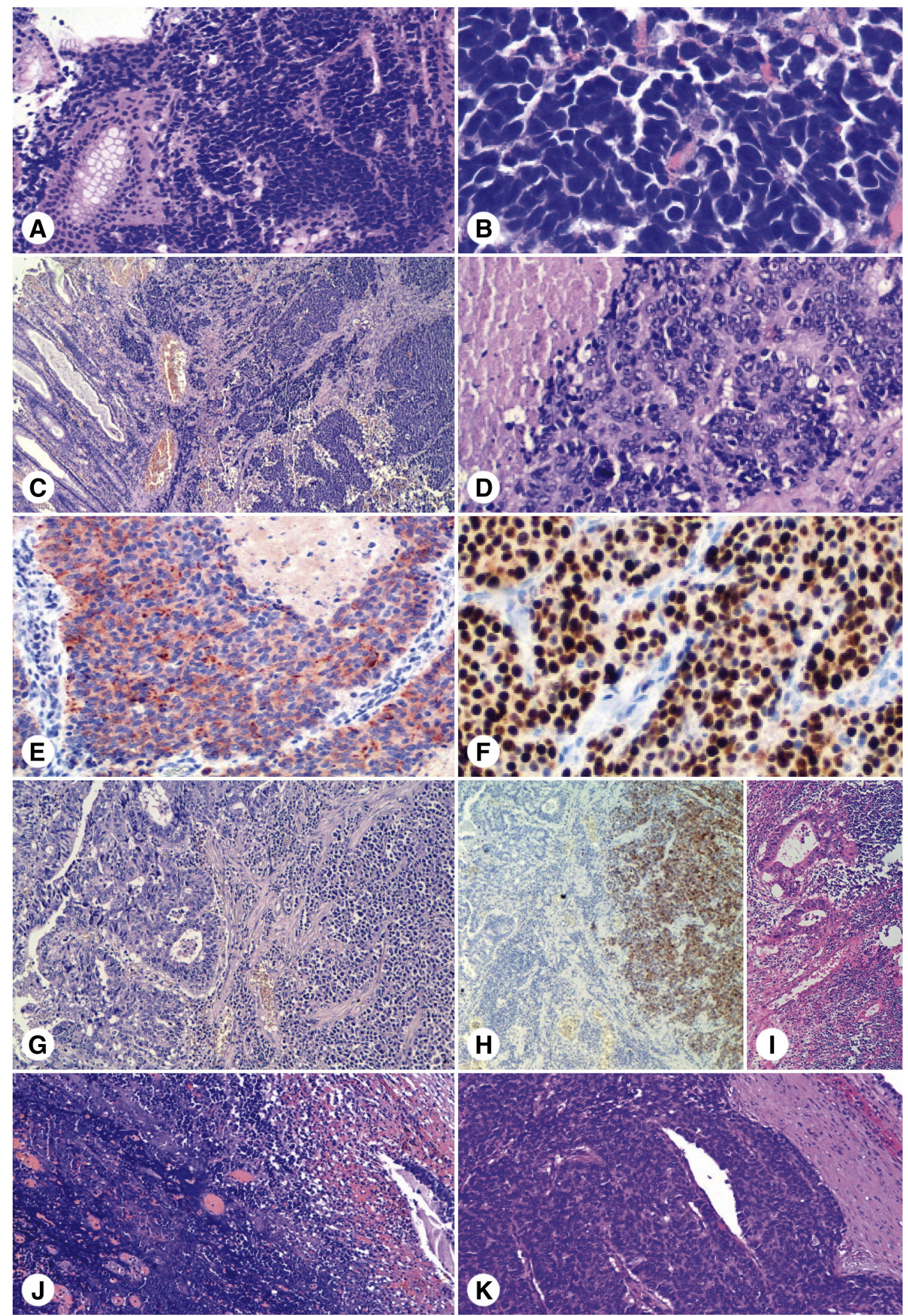
Table 1 Comparison of general characteristic of pulmonary and extrapulmonary (divided into GEP and urogenital tract locations) NECs

\begin{tabular}{llllll}
\hline Location & $\begin{array}{l}\text { Relative frequency } \\
\text { as compared to } \\
\text { NETs (carcinoids) }\end{array}$ & $\begin{array}{l}\text { Most prevalent type } \\
\text { (SCC vs LCNEC) }\end{array}$ & $\begin{array}{l}\text { Frequency of mixed } \\
\text { NE and non-NE } \\
\text { features }\end{array}$ & $\begin{array}{l}\text { Etiologic/ } \\
\text { risk factors }\end{array}$ & Precursor lesions \\
\hline $\begin{array}{l}\text { Lung } \\
\text { GEP }\end{array}$ & $\begin{array}{l}\text { More frequent } \\
\text { Less frequent }\end{array}$ & SCC & Very rare & $\begin{array}{l}\text { Cigarette smoking } \\
\text { Unknown }\end{array}$ & $\begin{array}{l}\text { Unknown } \\
\text { Unknown (possibly divergent } \\
\text { differentiation from adenocarcinoma) }\end{array}$ \\
$\begin{array}{l}\text { Urogenital } \\
\text { tract }\end{array}$ & More frequent & SCC & Frequent & $\begin{array}{l}\text { Unknown (possibly divergent } \\
\text { differentiation from carcinoma } \\
\text { subtypes) }\end{array}$ \\
\hline
\end{tabular}

conditions made of either small or large cells in individual organs, which may be problematic especially in cytology [19] or tiny biopsy specimens. In practical terms, it was claimed that the distinction between SCC and LCNEC is an apparently useless exercise, not only due to the similar clinical behavior reported above but also because many cases (indeed probably the majority of them) actually contain mixed cell populations, all sharing more or less evident NE features but displaying various cell sizes. In any case, a full range of options is possible, including pure SCC (former "oat cell") cancers on the one side and LCNEC on the other. In between, various combinations of small and large cell carcinomas may occur, covering the whole spectrum of cell sizes and having variable tumor architecture and cytological features. As a matter of fact, similar to what is observed in the lung, small cell EPNEC are usually neoplasms with a diffuse (solid or noncohesive) growth and finely granular nuclei lacking evident nucleoli. By contrast, large cell EPNEC present a more structured architecture (solid, trabecular, or organoid) and frequently large nuclei with hyperchromatic nucleoli.

The occurrence of EPNEC may also create differential diagnostic problems with poorly differentiated forms of their respective nonendocrine carcinomas or other malignancies such as hematological and mesenchymal neoplasms. As an example, small cell EPNEC in the bladder may be easily misdiagnosed as urothelial carcinoma [20], also because often a combination of these two forms exists (see also below).

Concerning the differential diagnoses mentioned above, there are no markers useful to discriminate small cell from large cell cases. Both display an epithelial immunoprofile, with wide spectrum cytokeratin expression, which may occasionally have a paranuclear dot-like distribution, especially in the case of SCC. Conversely, high-molecularweight cytokeratins (types 1, 5, 10, 14 of the Moll's catalog) are typically absent in the vast majority of NE differentiated carcinomas irrespective of the location [21,22]. Among NE markers, chromogranin A (more often with a focal paranuclear dot-like pattern unmasked by heat-induced antigen retrieval procedures) and synaptophysin are the most reliable molecules supporting the morphological evaluation, while neuron-specific enolase (NSE) and CD56 are sensitive but much less specific. Interestingly, up to $80 \%$ of EPNEC express the thyroid- and lung-specific marker TTF-1, thus limiting its usefulness in the definition of the primary location in the cases of NEC of unknown primary origin $[23,24]$.

An additional relevant challenge for pathologists is the differential diagnosis between high-grade NECs and welldifferentiated, low-grade NE neoplasms ("carcinoid"). This is not an obvious exercise in the daily pathology practice, especially when facing small endoscopic biopsies or needle aspirates from metastatic sites (eg, liver). In fact, cases of well-differentiated NE tumors (NETs) made of small cells do exist as either the result of artifactual cellular size changes (frequent in small biopsies or cytological specimens) or, more rarely, as a special small cell variant of such tumors. In surgical specimens, the diagnosis is generally easy, in the presence of an organoid or trabecular growth of low-grade NETs but may not be straightforward in preoperative specimens. Although not specifically addressed for tumors in extrapulmonary locations, a study of 7 pulmonary carcinoid tumors wrongly interpreted as SCCs in the biopsy, but confirmed as low-grade NETs in the surgical specimen, showed that Ki-67 index is the most reliable marker for a differential diagnosis of high-grade carcinomas from carcinoid tumors [25].

In addition, cases exist of well-differentiated NETs having a borderline number of mitoses and/or extensive necrosis, which may induce the suspicion of an EPNEC. The usual approach is to perform an accurate mitotic count usefully supported by a Ki-67 immunostaining. However, with special reference to the GEP system, a grey zone (not well clarified by the WHO classification) exists in terms of proliferation between NEC (all Grade 3) and rare NETs showing a well-differentiated morphology but a Ki-67 labeling index higher than 20\% (thus by definition G3, too). In this latter case, an additional useful method might be to consider the pattern and intensity of reactivity for chromogranin $\mathrm{A}$, which is generally focal and/or located paranuclear in a dot-like fashion in high- 
grade EPNECs, while stronger and uniformly cytoplasmic in well-differentiated NETs.

\subsection{Issue 3}

\subsubsection{Problem: What is the real role of Ki-67 index in small versus large cell NEC?}

2.4.1.1. Solution: Mandatory use of Ki-67 index for grading GEP NEN, only. As a rule, $\mathrm{Ki}-67$ index is to be assessed in all GEP NE neoplasms [16] to define tumor grading, with an accurate manual count rather than with an "eyeballing" approach [26]. However, Ki-67 evaluation is not valuable to distinguish small from large cell NECs, and there are no specific recommendations for Ki-67 investigation in sites other than the GEP system.

A literature review of the reported $\mathrm{Ki}-67$ values in EPNEC is summarized in Table 2, based only on published papers clearly reporting Ki-67 values for small and/or large cell components in EPNECs. Despite the difficulty of comparing the various figures obtained by different authors (also due to different classification criteria for small and large cells, as well as different counting methods), it seems that the mean proliferative index of small cell patterned NECs is slightly higher than that of morphologically proven LCNECs originated from pancreas, larynx, bile ducts, gastrointestinal tract, parotid, and urogenital tract $(70.9 \%$ versus $62 \%$ ).

\subsection{Issue 4}

2.5.1. Problem: How to classify EPNEC combined with adeno-, squamous, or urothelial carcinoma?

2.5.1.1. Solution: Heterogeneous criteria exist in different organs; favor morphological parameters and appropriate immunophenotypes. One of the most challenging (and also difficult to identify and treat) situation is the combination of NEC with a more or less well-represented non-NE component. Such component may be totally separated from the EPNEC (collision tumor) but more often is intermingled with the NEC population and indeed may not be readily apparent. This is especially true in cases of EPNEC combined with poorly differentiated non-NE components (for example basaloid squamous carcinoma of the uterine cervix or undifferentiated urothelial carcinoma).

For the pathological diagnosis of such cases, a first clue is to identify the NE cell population as such, and then the relative proportions of the exocrine and endocrine components are to be determined [49].

In the GEP area, this step is mandatory for the purpose of identifying so-called MANECs (mixed adeno-NEC), being at least $30 \%$ of each component required for rendering such a diagnosis in any given mixed tumor. In the stomach, mixed tumors follow a behavior intermediate between pure LCNEC (the most aggressive subgroup) and conventional gastric adenocarcinoma [7]. In the colon and rectum, the extent of

Table 2 Review of reported small versus large cell EPNECs with Ki-67 index evaluation

\begin{tabular}{|c|c|c|c|c|}
\hline \multirow[t]{2}{*}{ Ref } & \multirow[t]{2}{*}{ No. of cases } & \multirow[t]{2}{*}{ Location } & \multicolumn{2}{|c|}{ Ki-67 index (\%) in different components } \\
\hline & & & Small cell & Large cell \\
\hline Nagao et al 2000 [27] & 2 & Parotid & - & $55.3(53.4-57.1)$ \\
\hline Papotti et al 2000 [28] & 2 & Gallbladder & - & $60.5(50-71)$ \\
\hline Crafa et al 2003 [29] & 1 & Rectum & - & 50 \\
\hline Soriano et al 2004 [30] & 10 & Bladder & $33(15-70)$ & - \\
\hline Sugawara et al 2004 [31] & 1 & Ampulla of Vater & 54 & - \\
\hline Fernandez-Figueras et al 2005 [32] & 23 & Bladder/lung & 64.7 & - \\
\hline Stachs et al $2005[33]$ & 1 & Endometrium & 50 & - \\
\hline Lee et al 2009 [34] & 1 & Bladder & - & 40 \\
\hline Miyamoto et al 2006 [35] & 1 & Rectum & - & 87.8 \\
\hline Malhotra et al 2008 [36] & 1 & Liver & 90 & - \\
\hline Kozyrakis et al 2009 [37] & 1 & Bladder & 70 & - \\
\hline Yamaguchi et al 2009 [38] & 1 & Breast & 85 & - \\
\hline Lewis et al 2010 [39] & 10 & Larynx & - & $64.2(10-100)$ \\
\hline Righi et al 2010 [40] & 11 & Breast & $58(40-75)$ & - \\
\hline Stojsic et al 2010 [41] & 1 & Ampulla of Vater & - & 41 \\
\hline Terada 2010 [42] & 1 & Endometrium & - & 80 \\
\hline Terada $2011[43]$ & 1 & Esophagus & 100 & - \\
\hline Albisinni et al 2012 [44] & 1 & Prostate & 100 & - \\
\hline Benkel et al2012 [45] & 1 & Gallbladder & 70 & - \\
\hline Jianu et al 2012 [46] & 1 & Stomach & - & 90 \\
\hline Samad et al 2012 [47] & 1 & Bile ducts & - & 70 \\
\hline Yachida et al 2012 [10] & 19 & Pancreas & $67(\mathrm{n}=9)(55.1-85.8)$ & $43.4(n=10)(20-68.4)$ \\
\hline Yamamoto et al h2012 [48] & 1 & Pancreas & 80 & - \\
\hline Mean values & 93 cases & & 70.9 & 62 \\
\hline
\end{tabular}


the NE component (within the $30 \%$ rule) is not a predictor of behavior, and even a minor high-grade NE cell population was found able to metastasize [50]. In such location, the prognosis was comparable between MANEC (mixed adenoneuroendocrine carcinoma) and NEC, with a better prognosis in cases whose NE component was made of large cells [9]. Very few cases of concurrent adenocarcinoma and NEC in the hepatobiliary organ were reported [51].

In other locations, there are either different diagnostic rules or none. NE breast carcinoma is one of the several variants of this neoplasm and is defined as a tumor having NE morphological features necessarily associated with the immunohistochemical expression of NE markers in at least $50 \%$ of the tumor [18]. Such tumor type may display variable morphological patterns, including high-grade NEC of the large or small cell type. These latter are generally pure forms of primary breast EPNECs and therefore the NE cell population largely exceeds the required $50 \%$ and reaches $90 \%$ to $100 \%$. The other NE breast carcinomas are rather classical ductal or lobular carcinomas combined with a prominent (>50\%) NE cell component having mucinous, trabecular, alveolar, or solid patterns, which morphologically have little to do with the currently discussed small or large cell NE cancers [40].

In the thymus, the definition of combined exocrine-NEC, as part of thymic carcinoma (type $\mathrm{C}$ ), is rather generic, being restricted to the recognition of "two distinct areas, each corresponding to one of the histological types, including NEC" [52].

In the urogenital tract, combined carcinomas are as common as pure forms of EPNEC. In the prostate, EPNECs occur as either pure SCC (57\%) or combined with an adenocarcinoma having a high $(\geq 8)$ Gleason score, according to the largest published series of 95 cases [12]. In the bladder, no criteria are mentioned for the definition of mixed NEC: SCCs combined with urothelial, squamous, or adenocarcinoma occur more frequently $(70 \%)$ than pure forms [53], and the trend is similar for the even rarer LCNEC [54].

Similarly, in the ovary and in the uterine cervix there are no specific rules. In the latter, the NE component in an otherwise squamous cell carcinoma has been described to range from focal (17\%) to half a tumor, but NE differentiation was associated with an adverse prognosis irrespective of the extension [55].

\subsection{Issue 5}

\subsubsection{Problem: Does molecular signature keep separate small and large cell EPNEC?}

2.6.1.1. Solution: There are insufficient published data on this issue. Published genetic data are mostly dealing with mixed/combined exocrine-NECs, while separate analyses of large and small cell components within the same NET or comparison of genetic profiles in SCC versus LCNEC are lacking or are restricted to the pulmonary location, where a genetic similarity between SCC and LCNEC components within individual tumors is seen [56]. On the contrary, different genetic abnormalities in chromosomes $3 p$ and $5 q$ were found between pulmonary small and LCNECs, with only some overlapping features [57]. Moreover, data on a large series of lung SCC and LCNEC demonstrated that gene expression profiles are heterogeneous in the 2 forms and cluster analysis was unable to separate the two entities, but rather identified clinically distinctive subgroups [58].

In extrapulmonary locations, only a single recent study [10] analyzed 19 pancreatic NECs (9 small and 10 large cells), as well as 11 well differentiated NETs, for alterations of KRAS, CDKN2A/p16, P53, SMAD4/DPC4, DAXX, $A T R X, P T E N, B c l 2$, and $R B 1$ genes. Small and large cell NECs had genetically similar profiles but distinct from those observed in well-differentiated NETs. Other studies are restricted to single case reports, such as esophageal [43] and endometrial [42] EPNECs, that were investigated for KIT and PDGFRA gene status, finding no mutations. Finally, some cytogenetic differences were reported between primary pulmonary and extrapulmonary SCC [59]. Overall, the current knowledge does not support or disprove a molecular separation of small and large cell pulmonary nor extrapulmonary NECs.

\subsection{Issue 6}

\subsubsection{Problem: Any clinical meaning of distinguishing small and large cell NEC (in terms of behavior or therapeutic strategy)?}

2.7.1.1. Solution: Yes, for differential diagnosis purposes. Probably yes for tuning chemotherapy protocols; in the future, personalized treatments are expected. Having defined the criteria for taking small cell apart from large cell carcinoma forms, the next question arises if this really matters. The reason for this question relies on the comparable overall survival for surgically resected pulmonary SCC and LCNEC, with figures of approximately $35 \%$ and $40 \%$, respectively [60]. In this scenario, however, relatively recent reports seem to indicate a unique response rate of EPNEC to chemotherapy protocols conventionally used for pulmonary SCC [61].

Running through therapy-oriented studies on EPNEC available in the literature, it can be concluded that the treatment of EPNEC of the small cell type does not differ from the pulmonary counterpart [62-64] with response rates and global prognosis in general overlapping with those reported for lung SCC, even though some authors reported poorer results [65]. Since LCNECs of the lung, at least in their advanced stage, are also treated similarly to SCC [66], the whole spectrum of EPNEC generally undergoes the same chemotherapy approach. Indeed, some reports indicate that despite that the chemotherapy protocols are quite similar, response to therapy is different and the stability of disease after completion of chemotherapy may follow a different course $[61,63,67]$.

The first report on EPNEC therapy goes back to 1991 when Moertel and coworkers [68] firstly proposed platinum- 
etoposide regimens in NEC and identified a $67 \%$ response rate with a median survival of 19 months. These apparently excellent results were subsequently confirmed in 41 EPNEC patients who displayed a $42 \%$ response rate and a 15 -month median survival [69]. Nowadays, according to the North American Neuroendocrine Tumor guidelines [64], first-line systemic chemotherapy with a platinum agent (cisplatin or carboplatin) and etoposide is recommended for most EPNEC patients with metastatic-stage disease; however, response durations are often short. Sequential or concurrent chemoradiation is recommended for patients with locoregional disease [70].

Unfortunately, more recent studies reported less favorable clinical results. In 21 unresectable or recurrent hepatobiliary and pancreatic EPNECs, combination chemotherapy with cisplatin and etoposide provided a $14 \%$ response rate and a median overall survival of 5.8 months [71]. Comparing the efficacy of a platinum-containing regimen in 41 advanced EPNECs with that of SCC of the lung, the response rates were much worse in the former (31\% versus 78\%) [61]. This remarkable discrepancy might be due to the different nature of the 2 tumors (classical pulmonary SCCs are highly chemosensitive undifferentiated neoplasm, while EPNEC include more heterogeneous cancer subtypes), or to the anatomical location of the tumors, as partially confirmed by the worse response of hepatobiliary and pancreatic NECs ( $12 \%$ versus $57 \%$ for the other locations).

In a review of over 500 reported NETs with an unknown primary, despite the heterogeneity in terms of histology, grade, anatomic site, and tumor biology, it was found that most cases were managed with platinum-based regimens. The 294 patients with follow-up information had a median survival of 15.5 months, comparable to that reported for high-grade pulmonary and extrapulmonary NECs, even if the identification of the primary location or tumor type (small versus large cell type) was missing [72].

In a large series of 179 uterine cervix SCC, a mean progression-free survival of 16 months and a cancer-specific survival of 25 months were observed after a treatment based on platinum and etoposide and concurrent chemo- and radiation therapy further improved survival (up to $75 \%$ ). Mixed small cell and squamous cell carcinoma patterns were recognized in 47 of 179 cases, but this feature did not affect response rates [15].

\subsection{Issue 7}

\subsubsection{Problem: Any predictive factor of response to therapy in EPNEC?}

2.8.1.1. Solution: Assess proliferation index in all cases; in the future, personalized treatments are expected. In the large series of GEP NEC analyzed in the NORDIC study [63] a negative prognostic role of performance status, colorectal primary, elevated platelet, and lactose dehydrogenase (LDH) levels was observed. Proliferation index differed in terms of impact on survival and response to chemotherapy. In fact, it was found that Ki-67 index at a cut-off of $>55 \%$ was a positive predictor of response to platinum-based regimens ( $15 \%$ versus $42 \%$ comparing $<55 \%$ versus $>55 \% \mathrm{Ki}-67$, respectively), but patients with Ki-67 $<55 \%$ had a significantly longer survival compared with patients with higher Ki-67 levels (14 versus 10 months). Unfortunately, in this study no morphological review of the cases was performed, thus leaving the question open as to the prevalent histological type of tumors associated with a better response.

With regard to molecular targets of chemotherapeutic agents, it has been reported that pulmonary SCC are not responsive to pemetrexed and in general to antifolate drugs [73]. This was supported by the observation that high-grade NEC of the small and large cell type and of both pulmonary and GEP origin express high levels of thymidylate synthase, the most important target molecule of antifolates [74], thus supporting the usefulness of assessing the intratumoral expression levels of known targets, to better define the therapeutic strategy and/or predict response to different agents. Recent data are emerging with regard to the activation of intracellular signaling pathways as possible targets of specific treatments. A high phospho-mammalian target of rapamycin expression was reported in 9 poorly differentiated (large cell type) GEP NEC [75], suggesting that mammalian target of rapamycin could be explored as a possible therapeutic target in this subtype, as already well known for low-grade NETs.

\section{Conclusions}

i. based on both clinical and pathological findings and from a practical point of view, a common terminology is advisable for pure extrapulmonary high-grade NECs, using the acronym EPNEC and a subsequent distinction into small and large cell subtypes;

ii. similar to the lung, small and large cell EPNECs differ histologically by cell size, architecture, and nuclear features, although morphologically intermediate cases exist and the general genetic background, as well as the clinical behavior, are similar in the 2 forms;

iii. recognition of mixed NE/non-NE forms in extrapulmonary locations is based on morphology and appropriate immunophenotype; due to its relatively high frequency, it should be excluded by extensive sampling, and the relative proportions on NE and nonNE components should be reported in any case to better understand the impact on clinical behavior and response to treatment(s);

iv. immunohistochemistry is useful to distinguish EPNEC from poorly differentiated non-NECs (using NE markers) and from well-differentiated NETs (using $\mathrm{Ki}-67$, especially in small tissue fragments/cytological samples), but not to differentiate small and large cell EPNEC forms;

v. the pathogenesis of EPNEC is unclear and possibly different from that of pulmonary NECs; 
vi. platinum-based chemotherapy represents the most commonly used therapeutic approach in EPNEC (both small and large cell types), based on similarity between EPNEC and pulmonary SCC. However, some increasing evidence seem to indicate that response to therapy and prognosis are different between pulmonary and extrapulmonary NEC and possibly between EPNEC of the small and large cell types.

\section{References}

[1] Volante M, Righi L, Berruti A, Rindi G, Papotti M. The pathological diagnosis of neuroendocrine tumors: common questions and tentative answers. Virchows Arch 2011;458:393-402.

[2] Travis WD. Update on small cell carcinoma and its differentiation from squamous cell carcinoma and other non-small cell carcinomas. Mod Pathol 2012;25(Suppl 1):S18-30.

[3] Travis WD, Linnoila RI, Tsokos MG, et al. Neuroendocrine tumors of the lung with proposed criteria for large cell neuroendocrine carcinoma. An ultrastructural, immunohistochemical, and flow cytometric study of 35 cases. Am J Surg Pathol 1991;15:529-53.

[4] Frazier SR, Kaplan PA, Loy TS. The pathology of extrapulmonary small cell carcinoma. Semin Oncol 2007;34:30-8.

[5] Quinn AM, Blackhall F, Wilson G, et al. Extrapulmonary small cell carcinoma: a clinicopathological study with identification of potential diagnostic mimics. Histopathology 2012;61:454-64.

[6] Maru DM, Khurana H, Rashid A, et al. Retrospective study of clinicopathologic features and prognosis of high-grade neuroendocrine carcinoma of the esophagus. Am J Surg Pathol 2008;32:1404-11.

[7] Jiang SX, Mikami T, Umezawa A, Saegusa M, Kameya T, Okayasu I. Gastric large cell neuroendocrine carcinomas: a distinct clinicopathologic entity. Am J Surg Pathol 2006;30:945-53.

[8] La Rosa S, Inzani F, Vanoli A, et al. Histologic characterization and improved prognostic evaluation of 209 gastric neuroendocrine neoplasms. HUM PATHOL 2011;42:1373-84.

[9] La Rosa S, Marando A, Furlan D, Sahnane N, Capella C. Colorectal poorly differentiated neuroendocrine carcinomas and mixed adenoneuroendocrine carcinomas: insights into the diagnostic immunophenotype, assessment of methylation profile, and search for prognostic markers. Am J Surg Pathol 2012;36:601-11.

[10] Yachida S, Vakiani E, White CM, et al. Small cell and large cell neuroendocrine carcinomas of the pancreas are genetically similar and distinct from well-differentiated pancreatic neuroendocrine tumors. Am J Surg Pathol 2012;36:173-84.

[11] Evans AJ, Humphrey PA, Belani J, van der Kwast TH, Srigley JR. Large cell neuroendocrine carcinoma of prostate: a clinicopathologic summary of 7 cases of a rare manifestation of advanced prostate cancer. Am J Surg Pathol 2006;30:684-93.

[12] Wang W, Epstein JI. Small cell carcinoma of the prostate. A morphologic and immunohistochemical study of 95 cases. Am J Surg Pathol 2008;32:65-71.

[13] Alijo Serrano F, Sanchez-Mora N, Angel Arranz J, Hernandez C, Alvarez-Fernandez E. Large cell and small cell neuroendocrine bladder carcinoma: immunohistochemical and outcome study in a single institution. Am J Clin Pathol 2007;128:733-9.

[14] Rekhi B, Patil B, Deodhar KK, et al. Spectrum of neuroendocrine carcinomas of the uterine cervix, including histopathologic features, terminology, immunohistochemical profile, and clinical outcomes in a series of 50 cases from a single institution in India. Ann Diagn Pathol 2013;17:1-9.

[15] Wang KL, Chang TC, Jung SM, et al. Primary treatment and prognostic factors of small cell neuroendocrine carcinoma of the uterine cervix: a Taiwanese Gynecologic Oncology Group study. Eur J Cancer 2012;48:1484-94.
[16] Bosman F, Carneiro F, Hruban R, Theise ND. WHO classification of tumours of the digestive system. Lyon, France: IARC press; 2010.

[17] Eble JN, Sauter G, Epstein JI, Sesterhenn IA. WHO classification of tumours of the urinary system and male genital organs. Lyon, France: IARC press; 2004

[18] Tavassoli FA, Devilee P. WHO classification of tumours of the breast and female genital organs. Lyon, France: IARC press; 2003.

[19] Khalbuss WE, Yang H, Lian Q, Elhosseiny A, Pantanowitz L, Monaco SE. The cytomorphologic spectrum of small cell carcinoma and large cell neuroendocrine carcinoma in body cavity effusions: a study of 68 cases. Cytojournal 2011;8:18.

[20] Thompson S, Cioffi-Lavina M, Chapman-Fredricks J, et al. Distinction of high-grade neuroendocrine carcinoma/small cell carcinoma from conventional urothelial carcinoma of urinary bladder: an immunohistochemical approach. Appl Immunohistochem Mol Morphol 2011;19: 395-9.

[21] Sturm N, Rossi G, Lantuejoul S, et al. 34BetaE12 expression along the whole spectrum of neuroendocrine proliferations of the lung, from neuroendocrine cell hyperplasia to small cell carcinoma. Histopathology 2003;42:156-66.

[22] Sapino A, Righi L, Cassoni P, Papotti M, Pietribiasi F, Bussolati G. Expression of the neuroendocrine phenotype in carcinomas of the breast. Semin Diagn Pathol 2000;17:127-37.

[23] McCluggage WG, Kennedy K, Busam KJ. An immunohistochemical study of cervical neuroendocrine carcinomas: Neoplasms that are commonly TTF1 positive and which may express CK20 and P63. Am J Surg Pathol 2010;34:525-32.

[24] Ordonez NG. Value of thyroid transcription factor-1 immunostaining in distinguishing small cell lung carcinomas from other small cell carcinomas. Am J Surg Pathol 2000;24:1217-23.

[25] Pelosi G, Rodriguez J, Viale G, Rosai J. Typical and atypical pulmonary carcinoid tumor overdiagnosed as small cell carcinoma on biopsy specimens: a major pitfall in the management of lung cancer patients. Am J Surg Pathol 2005;29:179-87.

[26] Tang LH, Gonen M, Hedvat C, Modlin IM, Klimstra DS. Objective quantification of the ki67 proliferative index in neuroendocrine tumors of the gastroenteropancreatic system: a comparison of digital image analysis with manual methods. Am J Surg Pathol 2012;36:1761-70.

[27] Nagao T, Sugano I, Ishida Y, et al. Primary large cell neuroendocrine carcinoma of the parotid gland: immunohistochemical and molecular analysis of two cases. Mod Pathol 2000;13:554-61.

[28] Papotti M, Cassoni P, Sapino A, Passarino G, Krueger JE, AlboresSaavedra J. Large cell neuroendocrine carcinoma of the gallbladder: report of two cases. Am J Surg Pathol 2000;24:1424-8.

[29] Crafa P, Milione M, Azzoni C, Pilato FP, Pizzi S, Bordi C. Pleomorph poorly differentiated endocrine carcinoma of the rectum. Virchows Arch 2003;442:605-10.

[30] Soriano P, Navarro S, Gil M, Llombart-Bosch A. Small cell carcinoma of the urinary bladder. A clinico-pathological study of ten cases. Virchows Arch 2004;445:292-7.

[31] Sugawara G, Yamaguchi A, Isogai M, Watanabe Y, Kaneoka Y, Suzuki M. Small cell neuroendocrine carcinoma of the ampulla of Vater with foci of squamous differentiation: a case report. J Hepatobiliary Pancreat Surg 2004;11:56-60.

[32] Fernandez-Figueras MT, Puig L, Musulen E, et al. Prognostic significance of p27Kip1, p45Skp2 and Ki67 expression profiles in Merkel cell carcinoma, extracutaneous small cell carcinoma, and cutaneous squamous cell carcinoma. Histopathology 2005;46:614-21.

[33] Stachs A, Makovitzky J, Briese V. Small cell carcinoma of the endometrium: light microscopic and immunohistochemical study of a case. Anticancer Res 2005;25:1823-5.

[34] Lee WJ, Kim CH, Chang SE, et al. Cutaneous metastasis from large cell neuroendocrine carcinoma of the urinary bladder expressing CK20 and TTF-1. Am J Dermatopathol 2009;31:166-9.

[35] Miyamoto H, Kurita N, Nishioka M, et al. Poorly differentiated neuroendocrine cell carcinoma of the rectum: report of a case and literal review. J Med Invest 2006;53:317-20. 
[36] Malhotra RK, Li W. Poorly differentiated gastroenteropancreatic neuroendocrine carcinoma associated with X-linked hyperimmunoglobulin M syndrome. Arch Pathol Lab Med 2008;132:847-50.

[37] Kozyrakis D, Papadaniil P, Stefanakis S, et al. Small cell carcinoma of the urinary tract: a case report. Cases Journal 2009;2:7743.

[38] Yamaguchi R, Tanaka M, Otsuka H, et al. Neuroendocrine small cell carcinoma of the breast: report of a case. Med Mol Morphol 2009;42:58-61.

[39] Lewis Jr JS, Spence DC, Chiosea S, Barnes Jr EL, Brandwein-Gensler M, El-Mofty SK. Large cell neuroendocrine carcinoma of the larynx: definition of an entity. Head Neck Pathol 2010;4:198-207.

[40] Righi L, Sapino A, Marchio C, Papotti M, Bussolati G. Neuroendocrine differentiation in breast cancer: established facts and unresolved problems. Semin Diagn Pathol 2010;27:69-76.

[41] Stojsic Z, Brasanac D, Bilanovic D, Mitrovic O, Stevanovic R, Boricic I. Large cell neuroendocrine carcinoma of the ampulla of Vater. Med Oncol 2010;27:1144-8.

[42] Terada T. Large cell neuroendocrine carcinoma with sarcomatous changes of the endometrium: a case report with immunohistochemical studies and molecular genetic study of KIT and PDGFRA. Pathol Res Pract 2010;206:420-5.

[43] Terada T. Neuroendocrine carcinoma of the esophagus: a case report with immunohistochemical and molecular genetic analyses of KIT and PDGFRA. Med Oncol 2011;28:509-12.

[44] Albisinni S, De Nunzio C, Tubaro A. Pure small cell carcinoma of the prostate: A rare tumor. Indian J Urol 2012;28:89-91.

[45] Benkel M, Brasch F, Neumann JD, Altendorf-Hofmann A, Sendt W. Poorly differentiated neuroendocrine small cell carcinoma of the gallbladder. Zentralbl Chir 2012;137:71-2.

[46] Jianu CS, Lange OJ, Viset T, et al. Gastric neuroendocrine carcinoma after long-term use of proton pump inhibitor. Scand J Gastroenterol 2012;47:64-7.

[47] Samad A, Kaplan A, Arain M, et al. Endoscopic ultrasound-guided fineneedle aspiration diagnosis of large cell neuroendocrine carcinoma of the gallbladder and common bile duct: report of a case. Diagn Cytopathol 2012 [E-pub ahead of print; http://dx.doi.org/10.1002/dc.22872].

[48] Yamamoto M, Miyagawa K, Hiura M, et al. Poorly differentiated neuroendocrine carcinoma of the pancreas responsive to combination therapy with gemcitabine and S-1. Intern Med 2012;51:727-32.

[49] Volante M, Rindi G, Papotti M. The grey zone between pure (neuro) endocrine and non-(neuro)endocrine tumours: a comment on concepts and classification of mixed exocrine-endocrine neoplasms. Virchows Arch 2006;449:499-506.

[50] Li Y, Yau A, Schaeffer D, et al. Colorectal glandular-neuroendocrine mixed tumor: pathologic spectrum and clinical implications. Am J Surg Pathol 2011;35:413-25.

[51] Harada K, Sato Y, Ikeda H, et al. Clinicopathologic study of mixed adenoneuroendocrine carcinomas of hepatobiliary organs. Virchows Arch 2012;460:281-9.

[52] Travis WD, Brambilla E, Muller-Hermelink KM. WHO classification of tumours of the lung, pleura, thymus and heart. Lyon, France: IARC press; 2004.

[53] Abrahams NA, Moran C, Reyes AO, Siefker-Radtke A, Ayala AG. Small cell carcinoma of the bladder: a contemporary clinicopathological study of 51 cases. Histopathology 2005;46:57-63.

[54] Martin IJ, Vilar DG, Aguado JM, et al. Large cell neuroendocrine carcinoma of the urinary bladder. Bibliographic review. Arch Esp Urol 2011;64:105-13.

[55] Horn LC, Hentschel B, Bilek K, Richter CE, Einenkel J, Leo C. Mixed small cell carcinomas of the uterine cervix: prognostic impact of focal neuroendocrine differentiation but not of Ki-67 labeling index. Ann Diagn Pathol 2006;10:140-3.

[56] D'Adda T, Pelosi G, Lagrasta C, et al. Genetic alterations in combined neuroendocrine neoplasms of the lung. Mod Pathol 2008;21:414-22.
[57] Hiroshima K, Iyoda A, Shida T, et al. Distinction of pulmonary large cell neuroendocrine carcinoma from small cell lung carcinoma: a morphological, immunohistochemical, and molecular analysis. Mod Pathol 2006;19:1358-68.

[58] Jones MH, Virtanen C, Honjoh D, et al. Two prognostically significant subtypes of high-grade lung neuroendocrine tumours independent of small cell and large cell neuroendocrine carcinomas identified by gene expression profiles. Lancet 2004;363:775-81.

[59] Brenner B, Tang LH, Klimstra DS, Kelsen DP. Small cell carcinomas of the gastrointestinal tract: a review. J Clin Oncol 2004;22:2730-9.

[60] Asamura H, Kameya T, Matsuno Y, et al. Neuroendocrine neoplasms of the lung: a prognostic spectrum. J Clin Oncol 2006;24:70-6.

[61] Terashima T, Morizane C, Hiraoka N, et al. Comparison of chemotherapeutic treatment outcomes of advanced extrapulmonary neuroendocrine carcinomas and advanced small cell lung carcinoma. Neuroendocrinology 2012;96:324-32.

[62] Brennan SM, Gregory DL, Stillie A, Herschtal A, Mac Manus M, Ball DL. Should extrapulmonary small cell cancer be managed like small cell lung cancer? Cancer 2010;116:888-95.

[63] Sorbye H, Welin S, Langer SW, et al. Predictive and prognostic factors for treatment and survival in 305 patients with advanced gastrointestinal neuroendocrine carcinoma (WHO G3): The NORDIC NEC study. Ann Oncol 2013;24:152-60.

[64] Strosberg JR, Coppola D, Klimstra DS, et al. The NANETS consensus guidelines for the diagnosis and management of poorly differentiated (high-grade) extrapulmonary neuroendocrine carcinomas. Pancreas 2010;39:799-800

[65] Ochsenreither S, Marnitz-Schultze S, Schneider A, et al. Extrapulmonary small cell carcinoma (EPSCC): 10 years' multi-disciplinary experience at Charite. Anticancer Res 2009;29:3411-5.

[66] Sun JM, Ahn MJ, Ahn JS, et al. Chemotherapy for pulmonary large cell neuroendocrine carcinoma: similar to that for small cell lung cancer or non-small cell lung cancer? Lung Cancer 2012;77:365-70.

[67] Deutschbein T, Unger N, Yuece A, et al. Chemotherapy in patients with progressive, undifferentiated neuroendocrine tumors: a singlecenter experience. Horm Metab Res 2011;43:838-43.

[68] Moertel CG, Kvols LK, O'Connell MJ, Rubin J. Treatment of neuroendocrine carcinomas with combined etoposide and cisplatin. Evidence of major therapeutic activity in the anaplastic variants of these neoplasms. Cancer 1991;68:227-32.

[69] Mitry E, Baudin E, Ducreux M, et al. Treatment of poorly differentiated neuroendocrine tumours with etoposide and cisplatin. Br J Cancer 1999;81:1351-5.

[70] Fazio N, Spada F, Giovannini M. Chemotherapy in gastroenteropancreatic (GEP) neuroendocrine carcinomas (NEC): A critical view. Cancer Treat Rev 2013;39:270-4.

[71] Iwasa S, Morizane C, Okusaka T, et al. Cisplatin and etoposide as firstline chemotherapy for poorly differentiated neuroendocrine carcinoma of the hepatobiliary tract and pancreas. Jpn J Clin Oncol 2010;40:313-8.

[72] Stoyianni A, Pentheroudakis G, Pavlidis N. Neuroendocrine carcinoma of unknown primary: a systematic review of the literature and a comparative study with other neuroendocrine tumors. Cancer Treat Rev 2011;37:358-65.

[73] Socinski MA, Smit EF, Lorigan P, et al. Phase III study of pemetrexed plus carboplatin compared with etoposide plus carboplatin in chemotherapy-naive patients with extensive-stage small cell lung cancer. J Clin Oncol 2009;27:4787-92.

[74] Ceppi P, Volante M, Ferrero A, et al. Thymidylate synthase expression in gastroenteropancreatic and pulmonary neuroendocrine tumors. Clin Cancer Res 2008;14:1059-64.

[75] Shida T, Kishimoto T, Furuya M, et al. Expression of an activated mammalian target of rapamycin (mTOR) in gastroenteropancreatic neuroendocrine tumors. Cancer Chemother Pharmacol 2010;65:889-93. 